\title{
Improvement of health-related quality of life in depression after transcranial magnetic stimulation in a naturalistic trial is associated with decreased perfusion in precuneus
}

Rémy Dumas ${ }^{1,2^{*}}$, Raphaëlle Richieri ${ }^{1,2,5}$, Eric Guedj ${ }^{3,4,5}$, Pascal Auquier ${ }^{2,6}$, Christophe Lancon ${ }^{1,2}$ and Laurent Boyer ${ }^{2,6}$

\begin{abstract}
Background: Assessing Health-related Quality of life (HRQoL) is necessary to evaluate care and treatments provided to patients with major depressive disorder (MDD), in addition to the traditional assessment of clinical outcomes. However, HRQoL remains under-utilized to assess the effectiveness of repetitive transcranial magnetic stimulation (rTMS) in research or in a routine clinical setting. The primary objective of this exploratory study on MDD was to investigate the impact of low-frequency rTMS on HRQoL using the SF-36 questionnaire. A secondary objective was to study the functional neural substrate underlying HRQoL changes using neuroimaging.

Methods: Fifteen right-handed patients who met DSM-IV criteria for MDD participated in the study. HRQoL was assessed using the SF-36, and regional cerebral blood (rCBF) flow using 99mTc-ECD-SPECT. Voxel based correlation was searched between concomitant changes in rCBF and in HRQoL after rTMS.

Results: Role-Physical Problems dimension showed a statistical significant improvement of $73.2 \%(p=0.001)$ and an effect size (Cohen's d) of 0.43, indicating moderate effect. Five SF-36 dimension scores and the two composite scores showed effect sizes ranged from 0.28 to 0.43 . Improvement of Mental Composite Score (MCS)-SF-36 after rTMS was correlated with a concomitant decrease of precuneus perfusion $(p<0.001)$. Post-hoc analyses confirmed that decreased perfusion in precuneus was correlated with improvement of HRQoL, especially for MCS $(r=-0.71$; $p<0.001)$, Mental Health $(r=-0.81 ; p<0.001)$ and Social Functioning $(r=-0.57 ; p=0.026)$ dimensions.

Conclusions: This study suggests low-frequency rTMS can improve HRQoL, through its role-physical problems dimension, in patients with MDD. This improvement is associated with a decreased perfusion of the precuneus, a brain area involved in self-focus and self-processing, arguing for a neural substrate to the impact of rTMS on HRQOL.
\end{abstract}

Keywords: Depression, Health-related quality of life, Repetitive Transcranial Magnetic Stimulation (rTMS), Single photon emission computed tomography (SPECT), Precuneus

\footnotetext{
* Correspondence: remy.dumas@ap-hm.fr

'Department of Psychiatry, Sainte-Marguerite University Hospital, Marseille 13009, France

${ }^{2}$ Aix-Marseille Univ, EA 3279 - Self-perceived Health Assessment Research Unit, Marseille 13005, France

Full list of author information is available at the end of the article
} 


\section{Background}

Major depressive disorder (MDD) [1] remains one of the leading causes of disability in developed countries despite pharmacological and psychological treatments [2]. A new alternative for depressed individuals is repetitive transcranial magnetic stimulation (rTMS), a noninvasive well-tolerated technique [3-5]. rTMS protocols have been developed using high-frequency stimulation (> $5 \mathrm{~Hz}$ ) of the left dorsolateral prefrontal cortex (DLPFC) or low-frequency $(<1 \mathrm{~Hz})$ of the right DLPFC. The choice of distinct frequency comes from electrophysiological data of the motor cortex, showing that high-frequencies may have an excitatory effect while lowfrequencies tend to suppress cortical excitability [6,7]. Effectiveness of rTMS has been investigated in most studies using clinical outcomes, such as change in depressive symptomatology $[8,9]$. Thereby, meta-analyses have highlighted a threshold of $50 \%$ decrease in symptom severity, in up to $76 \%$ of patients [10-12]. Interestingly, the efficiency of low-frequency rTMS stimulation of the right DLPFC and of high-frequency rTMS stimulation of the left DLPFC seems to be similar in depressed patients $[11,13,14]$.

On the other hand, Health-related Quality of life (HRQoL) questionnaires are considered valuable and necessary tools to evaluate care and treatments provided to patients with MDD, in addition to the traditional assessment of clinical outcomes [15-17]. HRQoL may add interesting information that is oriented toward a more global service to individuals including the subjective experience of their illness, with regard to their symptoms but also their functioning embedded in social and environmental context [15]. However, HRQoL remains underutilized to assess the effectiveness of rTMS in research or in a routine clinical setting [8], and more globally in psychiatric clinical practice $[18,19]$. In congruence with prior investigations on HRQoL in MDD following antidepressant pharmacotherapy [20,21], only two recent studies, using the World Health Organization's Quality of Life Measure, brief version (WHOQOL BREF) [22] and the Medical Outcome Study 36-item Short Form (SF-36) $[23,24]$ questionnaires, have shown improvement in HRQoL domains following high-frequency rTMS $[8,25]$. These important findings should be confirmed using low-frequency rTMS which is better tolerated than highfrequency rTMS in terms of seizure risk [26].

The primary objective of this exploratory study was to investigate the impact of low-frequency rTMS on HRQoL using the SF-36 questionnaire, in patients with MDD. In addition, a better understanding of the mechanism underlying HRQoL changes is of particular interest in depression, as already proposed in schizophrenia $[27,28]$. A secondary objective was thus to study the functional neural substrate underlying HRQoL changes using neuroimaging with $99 \mathrm{~m}$ Tc-ethyl cysteinate dimer single-photon emission computed tomography $(99 \mathrm{mTc}-$ ECD-SPECT), a valuable tool to investigate the regional cerebral blood flow ( $\mathrm{rCBF}$ ), in a range of psychiatric disorders such as depression [29-31].

\section{Methods \\ Patients}

Fifteen right-handed patients, who met DSM-IV criteria for MDD participated in the study [1]. Inclusion criteria were: unipolar depression, Beck Depression Inventory-II (BDI-II) score $\geq 20$ [32], non-response to pharmacological treatment using a minimum of two distinctly different classes of antidepressant medications for episodes occurring at the time of enrolment, and written informed consent. Exclusion criteria were based on the following criteria: age under 18 years, MDD with psychotic features, psychiatric diagnosis other than MDD on Axis I of DSM-IV-TR [1], neurological disorders or convulsive disorders, and previous rTMS or electroconvulsive therapy treatments. Pretreatment with an antidepressant and/or mood stabilizer medication had to be stable for at least 4 weeks prior to entry in the study and remain unchanged throughout. The local Ethics Committee, Marseille, France approved the investigations. The project was conducted in accordance with the declaration of Helsinki and French Good Clinical Practice [33,34].

\section{rTMS treatment}

Low-frequency magnetic stimulation was performed using a figure eight-shaped water-cooled coil (Medtronic Inc., Minneapolis, MN, USA) to the right DLPFC. At the first rTMS session, the motor threshold was defined as the minimum intensity leading to the most prominent abduction of the left abductor pollicis brevis muscle after stimulation of the right motor cortex. This movement was determined by an electromyogram recording. During the treatment, the coil was positioned $5 \mathrm{~cm}$ anterior and in a parasagittal line from the motor cortex. rTMS was delivered with following characteristics: six 60-s trains at $1 \mathrm{~Hz}$ and at $120 \%$ of the motor threshold were applied in each session with a 30-s interval between the trains. Twenty treatment sessions were administered during 4 weeks (total pulses, 7200) [11].

\section{Data collection}

The following data were recorded: (1) demographic characteristics: gender and age, marital status and education level; (2) handedness determined by the Edinburgh Inventory [35]; (3) clinical characteristics: duration of illness, episode duration; (4) depression severity was assessed using the 21-item self-report Beck Depression Inventory (BDI-II) [32]. A score from 0 to 63 is calculated, with higher scores indicating more severe 
depressive symptoms; (5) HRQoL was assessed using the SF-36 [23,24]. SF-36 is a generic, self-administered, and worldwide-used questionnaire consisting of 36 items describing 8 dimensions: Physical Functioning (PF), Social Functioning (SF), Role-Physical Problems (RPP), RoleEmotional Problems (REP), Mental Health (MH), Vitality (VIT), Bodily Pain (BP), and General Health (GH). Each dimension is scored within a range of 0 (low HRQoL level) to 100 (high HRQoL level). Two component summary measures of SF-36, namely physical and mental composite scores (PCS-SF-36 and MCS-SF-36) are calculated.

Depression severity and HRQoL were assessed at baseline $(\mathrm{t} 0)$, and at the end of rTMS (t1).

\section{SPECT protocol and analysis}

Brain SPECT was performed in all patients, with the same camera, and under the same conditions, as previously described [29]. This exam was performed during the week before rTMS, and a second SPECT scan was obtained during the week after the end of the rTMS treatment. A voxel-by-voxel group study was then performed using Statistical Parametric Mapping (SPM) 8 (Wellcome Department of Cognitive Neurology, University College, London), running on Matlab (MathworksInc, Sherborn, MA).

Images were initially converted from the DICOM to the Analyze format using MRIcro (www.mricro.com), and transferred to SPM8. Data were then standardized with the Montreal Neurological Institute atlas, using a 12-parameter affine transformation, followed by nonlinear transformations and trilinear interpolation. Dimensions of resulting voxels were $2 \times 2 \times 2 \mathrm{~mm}$. Standardized data were then smoothed with a Gaussian filter (FWHM $=12 \mathrm{~mm}$ ), to blur individual variations in gyral anatomy, and to increase signal-to-noise ratio. The "proportional scaling" routine was used to control for individual variation in global brain perfusion.

Voxel based correlation was searched between concomitant changes in rCBF and in HRQoL after rTMS (PCS- and MCS-SF-36 changes). For this, brain SPECT, PCS and MCS baseline scores were subtracted with their respective post rTMS scores, and then divided by their respective baseline scores. The SPM $(\mathrm{T})$ maps were obtained at a height threshold of $\mathrm{p}<0.001$ (uncorrected) for the voxel, with at least 24 voxels within each cluster (forth FWHM of the Gaussian filter).

\section{Statistical analysis}

Data were expressed in proportion or mean and standard deviation (SD). Pre-post rTMS HRQoL comparisons were analyzed using two-tailed paired t-tests. Cohen's d effect sizes were then calculated $[8,36]$. As recommended, we considered d values from 0.15 to $0.39,0.4$ to 0.74 and from 0.74 to 1.1 as indicating small, moderate and large effect sizes, respectively $[8,36]$. Associations were then looked for between cluster(s) previously found correlated with PCS- and/or MCS-SF-36, and changes in dimensions of SF-36 and BDI-II, using Spearman's correlation tests. Spearman's correlation tests were used to determine the relationship between changes in BDI-II score and changes in dimensions and scores of SF-36. All the tests were two-sided. Statistical significance was defined at $p<0.05$. Statistical analysis was performed using the SPSS version 17.0 software package (SPSS Inc, Chicago, IL).

\section{Results}

\section{Patient characteristics}

The fifteen subjects (twelve women) presented pharmacoresistant unipolar depression with high severity (BDI$\mathrm{II}=36$; $\mathrm{SD}=9.8$ ). The average patient age was 49.8 years $(\mathrm{SD}=10.5)$, the duration of illness was 14.4 years $(\mathrm{SD}=$ 10.1), and the duration of current depressive episode was 38.2 months $(\mathrm{SD}=35.1)$. Twelve patients were single or divorced; ten patients had a high school or college education. Most patients $(n=13)$ received rTMS as addon treatment, and were treated under antidepressant monotherapy $(n=10)$, or combination of antidepressant and mood stabilizer $(n=3)$. Nine patients took benzodiazepines or hypnotics during rTMS treatment. Two patients were totally medication-free.

\section{Quality of life}

PCS showed improvement of $5.1 \%$, MCS of $13.9 \%$, and BDI-II of $13.1 \%$. Role-Physical Problems dimension showed a statistically significant improvement of $73.2 \%$ $(p=0.001)$ and an effect size (Cohen's d) of 0.43 , indicating moderate effect. General Health dimension remained fairly constant ( $2 \%$ increase), although the other dimensions increased from 11 (Social functioning) to $100 \%$ (Role-Emotional Problems). Five SF-36 dimension scores (Physical Functioning, Role-Emotional Problems, Mental Health, Bodily Pain, Vitality) and the two composite scores showed small to moderate effect sizes (Table 1 ). Significant correlations between BDI-II changes and HRQoL were found for the following dimensions: MCS $(\mathrm{r}=-0.71 ; \mathrm{p}=0.003), \quad \mathrm{MH} \quad(\mathrm{r}=-0.65 ; \mathrm{p}=0.009), \quad \mathrm{SF}$ $(\mathrm{r}=-0.58 ; \mathrm{p}=0.023)$, VIT $\quad(\mathrm{r}=-0.75 ; \mathrm{p}=0.001), \quad \mathrm{PF}$ $(\mathrm{r}=-0.56 ; \mathrm{p}=0.03)$ and $\mathrm{GH}(\mathrm{r}=-0.52 ; \mathrm{p}=0.04)$.

\section{Correlation between brain SPECT perfusion and HRQOL and clinical scores after rTMS}

HRQoL improvement for MCS-SF-36 was associated with a decreased perfusion of the precuneus $(\mathrm{p}<0.001$, uncorrected; $\mathrm{T}$-score $=3.85$ ) (Figure 1 ). No other significant correlation was found using whole brain analysis, in particular for PCS-SF-36 and for BDI-II. 
Table 1 Pre-post rTMS HRQoL comparisons $(n=15)$

\begin{tabular}{|c|c|c|c|c|}
\hline \multirow[t]{2}{*}{ SF-36 } & \multirow{2}{*}{$\frac{\text { Pre-rTMS }}{\text { Mean (SD) }}$} & \multirow{2}{*}{$\frac{\text { Post-rTMS }}{\text { Mean (SD) }}$} & \multirow[t]{2}{*}{$P$ value } & \multirow{2}{*}{$\frac{\text { Effect size (ES) }}{\text { (Cohen's d) }}$} \\
\hline & & & & \\
\hline$\overline{P F}$ & $53.3(25.4)$ & $62.0(28.5)$ & 0.193 & $+0.32^{a}$ \\
\hline RPP & $18.3(30.6)$ & $31.7(32.0)$ & 0.001 & $+0.43^{b}$ \\
\hline VIT & $19.3(15.1)$ & $25.0(17.1)$ & 0.270 & $+0.35^{a}$ \\
\hline $\mathrm{BP}$ & $40.9(21.2)$ & $49.9(28.7)$ & 0.125 & $+0.36^{a}$ \\
\hline $\mathrm{MH}$ & $25.6(12.0)$ & $32.8(22.8)$ & 0.247 & $+0.39^{a}$ \\
\hline REP & $13.3(24.6)$ & $26.7(36.1)$ & 0.159 & $+0.43^{b}$ \\
\hline SF & $29.2(21.0)$ & $32.5(25.4)$ & 0.638 & +0.14 \\
\hline $\mathrm{GH}$ & $28.6(21.1)$ & $29.1(19.5)$ & 0.937 & +0.02 \\
\hline MCS & $23.7(6.8)$ & $27(12)$ & 0.109 & $+0.31^{a}$ \\
\hline PCS & $38.9(8.1)$ & $40.9(9.2)$ & 0.177 & $+0.28^{a}$ \\
\hline
\end{tabular}

SF-36—PF Physical Functioning, RPP Role-Physical Problems, VIT Vitality, BP Bodily Pain, $M H$ Mental Health, REP Role-Emotional Problems, SF Social Functioning, GH General Health, MCS Mental Composite Score, PCS Physical Composite Score.

${ }^{\mathrm{a}}$ small effect size; ${ }^{\mathrm{b}}$ moderate effect size.

Spearman's correlations were then looked for between this cluster and the SF-36 dimension and BDI-II scores (Table 2). rCBF decrease of the precuneus was highly correlated with an HRQoL dimension increase of MCSSF-36 $(\mathrm{r}=-0.71 ; \mathrm{p}<0.001), \mathrm{MH}(\mathrm{r}=-0.81 ; \mathrm{p}<0.001)$ and $\mathrm{SF}(\mathrm{r}=-0.57 ; \mathrm{p}=0.026)$. On the contrary, precuneus perfusion was not significantly correlated with other SF-36 dimensions or with BDI-II score $(\mathrm{p}>0.05)$.

\section{Discussion}

Our study provides important information on the impact of rTMS on HRQoL in patients with MDD. Firstly, using a low-frequency rTMS administered on the right DLPFC, our findings tend to confirm the preliminary results of Berlim et al.[8], and Hadley et al.[25] using a highfrequency rTMS on the left DLPFC. Role-Physical Problems dimension improved significantly from baseline and showed moderate effect size. Five SF-36 dimension scores and the two composite scores showed effect sizes higher than 0.28 , suggesting a small to moderate "clinically" meaningful improvement of HRQoL. Although the HRQoL increase in our study showed less magnitude on physical, psychological and overall domains (respective Cohen's d, 0.44, 0.44, 0.57) than those found in Berlim's study [8] and on physical functioning, vitality, social functioning and mental health dimensions than in Hadley's study [25], precaution should be taken in this comparison. This difference may be explained by a higher effect of high-frequency rTMS on HRQoL than lowfrequency rTMS. However, the study of Berlim et al. did not use the same questionnaire, and the SF-36 and WHOQOL-BREF appear to measure distinct concepts related to HRQoL [37]. Concerning the study of Hadley et al., the baseline HRQoL levels were significantly higher than in our sample, and differential change in means from baseline may simply be due to skewness interacting with baseline differences [38]. Future studies should thus compare the impact of high and low-frequency rTMS on HRQoL using both questionnaires.

Moreover, this whole-brain voxel-based study is the first to investigate the neural substrate underlying HRQoL changes in patients with MDD treated by rTMS. We show that improvement of HRQoL for social and mental health dimensions SF-36-scores after rTMS is associated with a decreased perfusion of the precuneus. The precuneus has reciprocal connections with the DLPFC [39]. So, the decreased activity of the precuneus can result from the inhibitory effects of low-frequency rTMS over the right DLPFC, which can induce activity changes in distant brain regions via the neural pathways [40].

This report strengthens the scientific conceptual basis of HRQoL. The psychosocial construct of HRQoL, which required accurate self-assessment by individuals of their own inner feelings and state of well-being, appears consistent with precuneus involvement [31]. Indeed, precuneus has been mainly implicated in subjective experience and conscious self-representation [31,41]. In healthy subjects, precuneus is activated in self-related

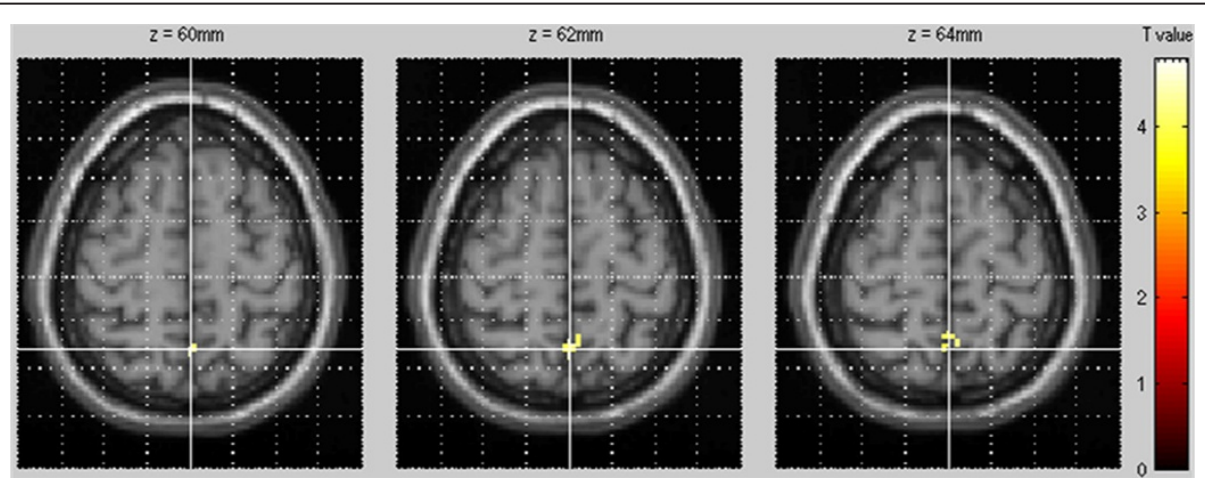

Figure 1 Anatomical localization of areas of decreased perfusion after rTMS correlated with concomitant HRQoL improvement $(p<0.001$, uncorrected; $k>24)$. 
Table 2 Correlations between changes in $\mathrm{rCBF}$ within the precuneus and changes in SF-36 dimensions and BDI-II

\begin{tabular}{lcc}
\hline & Precuneus cluster $\mathbf{R}^{\#}$ & $\boldsymbol{p}$ values \\
\hline SF-36 & & \\
PF & -0.25 & 0.380 \\
RPP & 0.04 & 0.881 \\
VIT & -0.10 & 0.712 \\
BP & 0.23 & 0.410 \\
MH & -0.81 & $<\mathbf{0 . 0 0 1}$ \\
REP & -0.37 & 0.179 \\
SF & -0.57 & $\mathbf{0 . 0 2 6}$ \\
GH & -0.10 & 0.712 \\
MCS & -0.71 & $<\mathbf{0 . 0 0 1}$ \\
PCS & 0.37 & 0.173 \\
BDI-II & 0.46 & 0.087 \\
\hline
\end{tabular}

\# R: Spearman's correlation coefficient.

SF-36-PF Physical Functioning, RPP Role-Physical Problems, VIT Vitality, BP Bodily Pain, MH Mental Health, REP Role-Emotional Problems, SF Social Functioning, GH General Health, MCS Mental Composite Score, PCS Physical Composite Score.

BDI-II. Beck Depression Inventory - II.

mental representations: at rest, through the default mode network [39], and during tasks about reflection on one's own personality traits and physical appearance [42]. Precuneus has been also involved in the subjective well-being and distress of patients with post-traumatic stress disorder [43].

Our findings attempt to provide some clues for a better understanding of the mechanism underlying the relationship between depression and HRQoL found in previous studies $[15,44,45]$. Indeed, patients with depression suffer from an increased self-focus (i.e. link negative affect and episodic memory deficit with an increased attention to the self) [46], and exaggerated self-processing (i.e. the appraisal of stimuli as strongly related to one's own person) [47]. Exaggerated self-referential processing (SRP) especially distorts interpretations of social cues and maintains social fears because of maladaptive cognitions regarding self (i.e. as socially incompetent) and others (i.e. as critical judges) [48]. Decreased activation in the precuneus could thus reflect a restored deactivation of the default mode network [49]. We hypothesize that decreased rCBF of the precuneus may be associated to a reduction of SRP allowing patients to focus their own attention on their environment, relatives and friends and then explaining an improvement of HRQoL. On the other hand, precuneus has been also involved in the theory of mind (ToM) $[50,51]$ which is conceived as a set of abilities that enable humans to understand other peoples' mental states and intentions. In particular, ToM is interrelated with self-focus attention and self-emotional awareness [51]. Moreover, previous studies have reported that ToM performance was associated with an increased perfusion of the precuneus $[28,31]$. Interestingly, Wolkenstein et al. [52] found that depressed patients were more accurate in decoding negative than neutral and positive mental states. The precuneus hypoperfusion found in our study may reflect a better attention for positive episodes and a decreased emotional response to negative thoughts [43] and thus be associated with improved mental health HRQoL concerning feelings of nervousness, peacefulness, and happiness $[28,31]$.

Our findings should be considered in treatment of patients with MDD, supporting the use of therapeutic interventions targeting self-focus and SRP, such as mindfulnessbased cognitive therapy [53] or cognitive base-therapy, to improve HRQoL. On the other hand, the impact of rTMS applied specifically to precuneus in patients with MDD on HRQoL should be investigated in future studies.

Lastly, the links between precuneus perfusion and HRQoL on the one hand, and those between HRQoL and depression on the other hand, help to better understand the mechanism of action of rTMS. The impact of rTMS may not only relieve the symptoms of MDD, but also affects other relevant psychosocial domains measured by HRQoL, which may in turn influence mood improvement. In accordance with this hypothesis, recent studies have shown HRQoL to be a prognostic factor associated with clinical outcome in various chronic diseases $[54,55]$. These findings may provide a support to integrate HRQoL in clinical practice, as complementary information to that traditionally collected in psychiatry.

\section{Limitations}

Several limitations have to be considered in this exploratory study. The first limitation is the small sample size $(\mathrm{n}=15)$; the lack of power may explain the contrast between the non-significant statistical results and the small to moderate level of effect sizes. Second, the absence of control group limits our ability to attribute the HRQoL changes exclusively to rTMS. However, although controlled trials are appropriate for establishing potentially causal associations, more naturalistic studies have the advantage of assessing "real life" situations of patients under treatment. These distinct limitations, also present in the previous reports $[8,25]$, should be considered in future studies. Third, we used the standard $5-\mathrm{cm}$ localization procedure for applying rTMS over the right DLPFC, instead of using a neuronavigational method, which seems to enhance response to rTMS [56]. Fourth, the unbalanced sample regarding gender might have bias our findings. However, the influence of gender on HRQoL is still unclear [57-59], and gender is not associated with difference in rTMS outcomes [60]. Sixth, some patients were receiving medical treatment during the study, including benzodiazepins that modify cortical 
excitability. Therefore, the effects of these medications on HRQoL and rCBF cannot be excluded. Finally, the use a self-rating subjective scale (BDI-II) to assess the severity of depression could be criticized. However, studies support a satisfactory convergent validity between BDI-II and Hamilton Depression Rating Scale or Clinical Global Impression [61,62].

\section{Conclusion}

This study suggests low-frequency rTMS can improve HRQoL, through its role-physical problems dimension, in patients with MDD. This improvement is associated with a decreased perfusion of the precuneus, a brain area involved in self-focus and self-processing, arguing for a neural substrate to the impact of rTMS on HRQoL.

\section{Abbreviations \\ HRQoL: Health-related quality of life; MDD: Major depressive disorder; DSM- IV: Diagnostic and statistical manual of mental disorder, fourth edition; rTMS: Repetitive transcranial magnetic stimulation; DLPFC: Dorsolateral prefrontal cortex; SPECT: Single-photon emission computed tomography; rCBF: Regional cerebral blood flow; SPM: Statistical parametric mapping; SD: Standard derivation; PF: Physical functioning; RPP: Role—Physical Problems; VIT: Vitality; BP: Bodily pain; MH: Mental health; REP: Role- emotional problems; SF: Social functioning; GH: General health; MCS: Mental composite score; PCS: Physical composite score; BDI-II: Beck depression inventory; SRP: Self-referential processing; ToM: Theory of Mind}

\section{Competing interests}

The authors have declared that there are no conflicts of interest in relation to the subject of this study.

\section{Authors' contributions}

$R D, R R, E G, P A$ and $L B$ wrote the manuscript. All authors designed the study and wrote the protocol. $R D, R R, E G, C L$ and $L B$ managed the literature searches and analyses. EG and LB managed the statistical analysis. All authors contributed to and approved the final manuscript.

\section{Author details}

'Department of Psychiatry, Sainte-Marguerite University Hospital, Marseille 13009, France. ${ }^{2}$ Aix-Marseille Univ, EA 3279 - Self-perceived Health Assessment Research Unit, Marseille 13005, France. ${ }^{3}$ Service Central de Biophysique et Médecine Nucléaire, La Timone University Hospital, Assistance Publique - Hôpitaux de Marseille, Marseille 13005, France. ${ }^{4}$ Aix-Marseille Univ, CERIMED, Marseille 13005, France. ${ }^{5}$ Aix-Marseille Univ, INT, CNRS UMR 7289, Marseille 13005, France. 'Department of Public Health, Assistance Publique Hôpitaux de Marseille, Marseille, France.

Received: 19 March 2012 Accepted: 16 July 2012

Published: 28 July 2012

\section{References}

1. American Psychiatric Association: DSM-IV. Diagnostic and Statistical Manual of Mental Disorders. 4th edition. Washington: American Psychiatric Association; 1994.

2. The World Health Report: Health Systems: Improving Performance. Geneva: World Health Organization; 2000.

3. George MS, Wassermann EM, Williams WA, Callahan A, Ketter TA, Basser P, Hallett M, Post RM: Daily repetitive transcranial magnetic stimulation (rTMS) improves mood in depression. Neuroreport 1995, 6:1853-1856

4. Rumi DO, Gattaz WF, Rigonatti SP, Rosa MA, Fregni F, Rosa MO, Mansur C, Myczkowski ML, Moreno RA, Marcolin MA: Transcranial magnetic stimulation accelerates the antidepressant effect of amitriptyline in severe depression: a double-blind placebo-controlled study. Biol Psychiatry 2005, 57:162-166.

5. Lefaucheur J-P, André-Obadia N, Poulet E, Devanne H, Haffen E, Londero A, Cretin B, Leroi A-M, Radtchenko A, Saba G, Thai-Van H, Litré C-F, Vercueil L,
Bouhassira D, Ayache S-S, Farhat W-H, Zouari H-G, Mylius V, Nicolier M, Garcia-Larrea L: French guidelines on the use of repetitive transcranial magnetic stimulation (rTMS): safety and therapeutic indications. Neurophysiol Clin 2011, 41:221-295.

6. Chen R, Classen J, Gerloff C, Celnik P, Wassermann EM, Hallett M, Cohen LG: Depression of motor cortex excitability by low-frequency transcranial magnetic stimulation. Neurology 1997, 48:1398-1403.

7. Pascual-Leone A, Valls-Solé J, Wassermann EM, Hallett M: Responses to rapid-rate transcranial magnetic stimulation of the human motor cortex. Brain 1994, 117(Pt 4):847-858.

8. Berlim MT, McGirr A, Beaulieu M-M, Turecki G: High frequency repetitive transcranial magnetic stimulation as an augmenting strategy in severe treatment-resistant major depression: a prospective 4-week naturalistic trial. J Affect Disord 2011, 130:312-317.

9. McLoughlin DM: Review: high frequency repetitive transcranial magnetic stimulation improves symptoms of major depression. Evid Based Ment Health 2009, 12:80-81.

10. Gross M, Nakamura L, Pascual-Leone A, Fregni F: Has repetitive transcranial magnetic stimulation (rTMS) treatment for depression improved? A systematic review and meta-analysis comparing the recent vs. the earlier rTMS studies. Acta Psychiatr Scand 2007, 116:165-173.

11. Schutter DJLG: Quantitative review of the efficacy of slow-frequency magnetic brain stimulation in major depressive disorder. Psychol Med 2010, 40:1789-1795.

12. Slotema CW, Blom JD, Hoek HW, Sommer IEC: Should we expand the toolbox of psychiatric treatment methods to include Repetitive Transcranial Magnetic Stimulation (rTMS)? A meta-analysis of the efficacy of rTMS in psychiatric disorders. J Clin Psychiatry 2010, 71:873-884.

13. Eche J, Mondino M, Haesebaert F, Saoud M, Poulet E, Brunelin J: Low- vs high-frequency repetitive transcranial magnetic stimulation as an addon treatment for refractory depression. Front Psychiatry 2012, 3:13.

14. Fitzgerald PB, Hoy K, Daskalakis ZJ, Kulkarni J: A randomized trial of the anti-depressant effects of low- and high-frequency transcranial magnetic stimulation in treatment-resistant depression. Depress Anxiety 2009, 26:229-234.

15. Papakostas GI, Petersen T, Mahal Y, Mischoulon D, Nierenberg AA, Fava M: Quality of life assessments in major depressive disorder: a review of the literature. Gen Hosp Psychiatry 2004, 26:13-17.

16. De Fruyt J, Demyttenaere K: Quality of life measurement in antidepressant trials. Is there an added value? Psychother Psychosom 2009, 78:212-219.

17. Kennedy SH, Eisfeld BS, Cooke RG: Quality of life: an important dimension in assessing the treatment of depression? I Psychiatry Neurosci 2001, 26(Suppl):S23-28.

18. Gilbody SM, House AO, Sheldon TA: Psychiatrists in the UK do not use outcomes measures. National survey. Br J Psychiatry 2002, 180:101-103.

19. Greenhalgh J, Long AF, Flynn R: The use of patient reported outcome measures in routine clinical practice: lack of impact or lack of theory? Soc Sci Med 2005, 60:833-843.

20. Berlim MT, Pargendler J, Brenner J, Fleck MPA: Significant improvement in the quality of life of Brazilian depressed outpatients 12 weeks following the start of antidepressants. Psychiatry Res 2007, 153:253-259.

21. Demyttenaere K, Andersen HF, Reines EH: Impact of escitalopram treatment on quality of life enjoyment and satisfaction questionnaire scores in major depressive disorder and generalized anxiety disorder. Int Clin Psychopharmacol 2008, 23:276-286.

22. Skevington SM, Lotfy M, O'Connell KA: The world health organization's WHOQOL-BREF quality of life assessment: psychometric properties and results of the international field trial. A report from the WHOQOL group. Qual Life Res 2004, 13:299-310.

23. Leplège A, Ecosse E, Verdier A, Perneger TV: The French SF-36 Health Survey: translation, cultural adaptation and preliminary psychometric evaluation. J Clin Epidemiol 1998, 51:1013-1023.

24. Ware JE Jr, Sherbourne CD: The MOS 36-item short-form health survey (SF-36). I. Conceptual framework and item selection. Med Care 1992, 30:473-483.

25. Hadley D, Anderson BS, Borckardt JJ, Arana A, Li X, Nahas Z, George MS Safety, tolerability, and effectiveness of high doses of adjunctive daily left prefrontal repetitive transcranial magnetic stimulation for treatmentresistant depression in a clinical setting. J ECT 2011, 27:18-25. 
26. Theodore $\mathrm{WH}$, Hunter $\mathrm{K}$, Chen R, Vega-Bermudez F, Boroojerdi B, Reeves-Tyer P, Werhahn K, Kelley KR, Cohen L: Transcranial magnetic stimulation for the treatment of seizures: a controlled study. Neurology 2002, 59:560-562.

27. Awad AG, Voruganti LNP: Measuring quality of life in patients with schizophrenia: an update. Pharmacoeconomics 2012, 30:183-195.

28. Boyer L, Richieri R, Faget C, Padovani R, Vaillant F, Mundler O, Lançon C, Auquier $P$, Guedj E: Functional involvement of superior temporal sulcus in quality of life of patients with schizophrenia. Psychiatry Res 2012, 202:155-160.

29. Richieri R, Boyer L, Farisse J, Colavolpe C, Mundler O, Lancon C, Guedj E: Predictive value of brain perfusion SPECT for rTMS response in pharmacoresistant depression. Eur J Nucl Med Mol Imaging 2011, 38:1715-1722.

30. Richieri R, Boyer L, Lançon C, Guedj E: Predict the outcome of depression after rTMS using neuroimaging: Issue of response or non-response? Brain Stimul 2012,

31. Faget-Agius C, Boyer L, Padovani R, Richieri R, Mundler O, Lançon C, Guedj E: Schizophrenia with preserved insight is associated with increased perfusion of the precuneus. J Psychiatry Neurosci 2012, 37:110125.

32. Beck AT, Steer RA, Ball R, Ranieri W: Comparison of beck depression inventories -IA and -II in psychiatric outpatients. J Pers Assess 1996, 67:588-597.

33. CNIL: Act $n^{\circ} 78-17$ of 6 January 1978 on Data Processing, Data Files and Individual Liberties (amended by the Act of 6 August 2004 relating to the protection of individuals with regard to the processing of personal data). France: Journal officiel de la République Française. Assemblée Nationale et Sénat: 2004.

34. World Medical Association: Declaration of Helsinki: ethical principles for medical research involving human subjects. JAMA 2000, 284:3043-3045.

35. Oldfield RC: The assessment and analysis of handedness: the Edinburgh inventory. Neuropsychologia 1971, 9:97-113.

36. Thalheimer W, Cook S: How to calculate effect sizes from published research articles: A simplified methodology:; 2002. August. Retrieved January 2, 2012 from http://work-learning.com/effect_sizes.htm.

37. Huang I-C, Wu AW, Frangakis C: Do the SF-36 and WHOQOL-BREF measure the same constructs? Evidence from the Taiwan population*. Qual Life Res 2006, 15:15-24.

38. Jamieson J: Dealing with baseline differences: two principles and two dilemmas. Int J Psychophysiol 1999, 31:155-161.

39. Cavanna AE, Trimble MR: The precuneus: a review of its functional anatomy and behavioural correlates. Brain 2006, 129:564-583.

40. Kito S, Hasegawa T, Koga Y: Neuroanatomical correlates of therapeutic efficacy of low-frequency right prefrontal transcranial magnetic stimulation in treatment-resistant depression. Psychiatry Clin Neurosci 2011, 65:175-182.

41. Lou HC, Luber B, Crupain M, Keenan JP, Nowak M, Kjaer TW, Sackeim HA Lisanby SH: Parietal cortex and representation of the mental self. Proc Natl Acad Sci USA 2004, 101:6827-6832.

42. Kjaer TW, Nowak M, Lou HC: Reflective self-awareness and conscious states: PET evidence for a common midline parietofrontal core. Neuroimage 2002, 17:1080-1086.

43. Nardo D, Högberg G, Flumeri F, Jacobsson H, Larsson SA, Hällström T, Pagani M: Self-rating scales assessing subjective well-being and distress correlate with rCBF in PTSD-sensitive regions. Psychol Med 2011, 45:2549-2561.

44. Ritsner M, Kurs R, Gibel A, Hirschmann S, Shinkarenko E, Ratner Y: Predictors of quality of life in major psychoses: a naturalistic follow-up study. $J$ Clin Psychiatry 2003, 64:308-315.

45. Ritsner $M$, Gibel A, Ratner Y: Determinants of changes in perceived quality of life in the course of schizophrenia. Qual Life Res 2006, 15:515-526.

46. Mor N, Winquist J: Self-focused attention and negative affect: a metaanalysis. Psychol Bull 2002, 128:638-662.

47. Lemogne C, Gorwood P, Bergouignan L, Pélissolo A, Lehéricy S, Fossati P: Negative affectivity, self-referential processing and the cortical midline structures. Soc Cogn Affect Neurosci 2011, 6:426-433.

48. Bögels SM, Mansell W: Attention processes in the maintenance and treatment of social phobia: hypervigilance, avoidance and self-focused attention. Clin Psychol Rev 2004, 24:827-856.

49. Delaveau P, Jabourian M, Lemogne C, Guionnet S, Bergouignan L, Fossati P: Brain effects of antidepressants in major depression: a meta-analysis of emotional processing studies. J Affect Disord 2011, 130:66-74.
50. Duval C, Desgranges B, Eustache F, Piolino P: Looking at the self under the microscope of cognitive neurosciences: from self-consciousness to consciousness of others. Psychol Neuropsychiatr Vieil 2009, 7:7-19.

51. Saxe R, Moran JM, Scholz J, Gabrieli J: Overlapping and non-overlapping brain regions for theory of mind and self reflection in individual subjects. Soc Cogn Affect Neurosci 2006, 1:229-234.

52. Wolkenstein $L$, Schönenberg M, Schirm E, Hautzinger M: I can see what you feel, but I can't deal with it: Impaired theory of mind in depression. $J$ Affect Disord 2011, 132:104-111.

53. Goldin P, Ramel W, Gross J: Mindfulness meditation training and selfreferential processing in social anxiety disorder: behavioral and neural effects. J Cogn Psychotherapy 2009, 23:242-257.

54. Boyer L, Millier A, Perthame E, Aballea S, Auquier P, Toumi M: Quality of life is predictive of relapse in schizophrenia. BMC Psychiatry, . In press.

55. Parshall MB, Mapel DW, Rice L, Williams A, O'Reilly J: Predictive validity of short-form health survey [36 items] scales for chronic obstructive pulmonary disease exacerbation. Heart Lung 2008, 37:356-365.

56. Fitzgerald PB, Hoy K, McQueen S, Maller JJ, Herring S, Segrave R, Bailey M, Been G, Kulkarni J, Daskalakis ZJ: A randomized trial of rTMS targeted with MRI based neuro-navigation in treatment-resistant depression. Neuropsychopharmacology 2009, 34:1255-1262.

57. Hadj Ammar M, Khammouma S, Nasr M: Depressive disorders and quality of life: a cross sectional study including 360 depressive patients followed at the psychiatry consultation of the Mahdia university hospital. Encephale 2008, 34:256-262.

58. Kuehner C, Buerger C: Determinants of subjective quality of life in depressed patients: the role of self-esteem, response styles, and social support. J Affect Disord 2005, 86:205-213.

59. Trivedi MH, Rush AJ, Wisniewski SR, Warden D, McKinney W, Downing M, Berman SR, Farabaugh A, Luther JF, Nierenberg AA, Callan JA, Sackeim HA: Factors associated with health-related quality of life among outpatients with major depressive disorder: a STAR*D report. J Clin Psychiatry 2006, 67:185-195.

60. Brunoni AR, Lopes M, Kaptchuk TJ, Fregni F: Placebo response of nonpharmacological and pharmacological trials in major depression: a systematic review and meta-analysis. PLOS ONE 2009, 4:e4824.

61. Furukawa TA: Assessment of mood: guides for clinicians. J Psychosom Res 2010, 68:581-589.

62. Hiroe T, Kojima M, Yamamoto I, Nojima S, Kinoshita Y, Hashimoto N, Watanabe N, Maeda T, Furukawa TA: Gradations of clinical severity and sensitivity to change assessed with the Beck Depression Inventory-II in Japanese patients with depression. Psychiatry Res 2005, 135:229-235.

doi:10.1186/1477-7525-10-87

Cite this article as: Dumas et al:: Improvement of health-related quality of life in depression after transcranial magnetic stimulation in a naturalistic trial is associated with decreased perfusion in precuneus. Health and Quality of Life Outcomes 2012 10:87.

\section{Submit your next manuscript to BioMed Central and take full advantage of:}

- Convenient online submission

- Thorough peer review

- No space constraints or color figure charges

- Immediate publication on acceptance

- Inclusion in PubMed, CAS, Scopus and Google Scholar

- Research which is freely available for redistribution 